\title{
The importance of relationship processes for lowering BMI over time in women with type 2 diabetes in a randomized controlled trial
}

Jeremy B. Yorgason

Brigham Young University - Provo

Jonathan G. Sandberg

Brigham Young University - Provo, jonathan_sandberg@byu.edu

Ruth S. Weinstock

SUNY Upstate Medical University

Paula M. Trief

SUNY Upstate Medical University

Follow this and additional works at: https://scholarsarchive.byu.edu/facpub

'siwrence Fisher

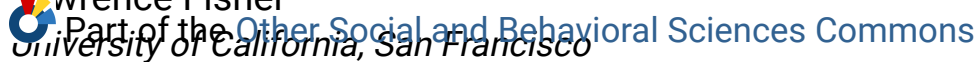

\section{Original Publication Citation}

Sergaxt,Rage. Bor Sadditional, autkors., Weinstock, R. S., Trief, P. M., Fisher, L., \& Hessler, D. (2019). The importance of relationship processes for lowering BMI over time in women with type 2 diabetes in a randomized controlled trial. Obesity research \& clinical practice, 13(6), 599-601.

\section{BYU ScholarsArchive Citation}

Yorgason, Jeremy B.; Sandberg, Jonathan G.; Weinstock, Ruth S.; Trief, Paula M.; Fisher, Lawrence; and Hessler, Danielle, "The importance of relationship processes for lowering BMI over time in women with type 2 diabetes in a randomized controlled trial" (2019). Faculty Publications. 4195.

https://scholarsarchive.byu.edu/facpub/4195

This Peer-Reviewed Article is brought to you for free and open access by BYU ScholarsArchive. It has been accepted for inclusion in Faculty Publications by an authorized administrator of BYU ScholarsArchive. For more information, please contact ellen_amatangelo@byu.edu. 


\section{Authors}

Jeremy B. Yorgason, Jonathan G. Sandberg, Ruth S. Weinstock, Paula M. Trief, Lawrence Fisher, and Danielle Hessler 


\section{Research Letter}

A B S T R A C T

Objective: Weight change may be affected by dyadic processes within couple relationships. The aim of this secondary data analysis was to explore trends in BMI across time, and assess whether relationship processes (i.e., relationship satisfaction, positive problem-solving), predict BMI trajectories in men and women.

Methods: Data are from 268 participants in the Diabetes Support Project, a randomized trial of behavioral intervention for individuals with type 2 diabetes (T2D) in poor glycemic control. For secondary analyses, BMI was measured at pre-treatment (baseline), 4 months (post-treatment), 8 months, and 12 months. Multiple relationship variables were measured at all time points and were modeled as predictors and correlates of change in BMI across time. Results: In general, BMI trajectories had higher starting values (intercepts) for females than for males in the sample $(b=-2.51, p<.05)$, and slopes trended downward from pre-treatment to 12 months $(b=-.09, p<.05)$. Downward trajectories of BMI were more pronounced for women with higher relationship satisfaction $(b=.05, p<.05)$ and higher positive problem solving skills $(b=.06, p<.05)$ at baseline. Change in relationship processes were not correlated with change in BMI across time.

Conclusion: For women with T2D in this behavioral intervention study, relationship process scores at the beginning of treatment predicted changes in BMI over time, with better problem solving and higher relationship satisfaction at baseline related to steeper decreases in BMI across treatment. Additional research is needed to understand how improving relationship interaction prior to diabetes treatment may positively influence weight loss during treatment.

(c) 2019 Published by Elsevier Ltd on behalf of Asia Oceania Association for the Study of Obesity.

\section{The importance of relationship processes for lowering BMI over time in women with type 2 diabetes in a randomized controlled trial}

\section{Introduction}

Some suggest that weight gain in marriage is a function of dyadic processes [1], and that relationship processes may play a role in weight reduction treatments [3]. A couples-based approach to treatment might add value [2-4]. The current study focuses on how relationship dynamics relate to BMI reduction among adults with type 2 diabets (T2D). We hypothesized that relationship processess would predict BMI reduction across time for individuals involved in T2D behavioral interventions, and explored whether the association differed by gender.

\section{Methods}

Data are from the Diabetes Support Project (DSP) [5], a randomized controlled trial of three telephone behavioral interventions (couples intervention, individual intervention, individual education intervention) to improve glycemic control. DSP trial design and primary outcome data were previously reported [5,6]. Enrolled participants $(\mathrm{N}=268)$ met the following criteria: diagnosed with T2D $>1$ year; baseline $\mathrm{A} 1 \mathrm{C}>7.5 \%$ (A1c measures glycemic control); $\geq 21$ years of age; literate/fluent in English; in a committed relationship for $\geq 1$ year; no severe interfering medical or psychiatric conditions; telephone access.

BMI $\left(\mathrm{kg} / \mathrm{m}^{2}\right)$ was measured at pre-treatment, 4-months (posttreatment), 8 and 12-months by measuring weight and height. Relationship satisfaction was measured using 4-items from the Revised Dyadic Adjustment scale $(\alpha=.75)$ [7]. Positive problem solving was measured using 4-items from the Conflict Resolution Inventory $(\alpha=.76)[4]$.
Mixed regression models were estimated, with gender and relationship processes predicting initial levels of BMI and change in BMI across the four time points. We controlled for intervention arm, years since diabetes diagnosis, age, income, years in the relationship, treatment adherence, diabetes treatment (insulin vs. not), and baseline glycemic control.

\section{Results}

Participants had been diagnosed with T2D for a mean of $12.41(\mathrm{SD}=7.9)$ years and married/partnered for a mean of 25.5 $(S D=14.8)$ years. Females $(n=103,38 \%)$ had higher mean BMI than males $(\mathrm{p} \leq .01)$ at pre-treatment. Approximately $30 \%$ of the sample were racial/ethnic minorities [5].

The average BMI at baseline was just below 36 , and declined by $1 / 10$ th of a point $(b=.09, t=-2.067 ; p<.05)$ per time-point (see Model 1, Table 1). As seen in Models 2 and 4, gender predicted the intercept of BMI indicating that females averaged around 2 points $(\mathrm{b}=1.99, t=-2.058 ; p<.05)$ higher BMI than males at baseline. As seen in Models 3 and 5, gender interacted with relationship satisfaction $(\mathrm{b}=.06, t=2.073 ; p<.05)$ and positive problem solv$\operatorname{ing}(\mathrm{b}=.06, t=1.875, p<.10)$, indicating that relationship processes were linked with BMI slopes for females. Females with higher relationship satisfaction and higher positive problem solving at baseline showed a significant decrease in BMI across time (Fig. 1). Tests of simple slopes indicated that female BMI changes across time were statistically significant at a trend level $(p<.10)$, and that these represented approximately $1 / 10$ th of a standard deviation change across the course of the study. Additional analyses in which waist circumference and weight were modeled as outcomes showed similar patterns of results (available upon request).

Dual change score models [8] were estimated wherein change in relationship processes from pretreatment to 12-month follow up were correlated with change in BMI over time. Changes in rela- 
Table 1

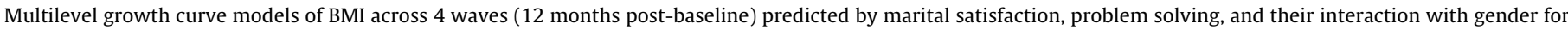
the full sample $(\mathrm{N}=268)$.

\begin{tabular}{|c|c|c|c|c|c|c|c|c|}
\hline & Model 1 & & Model 2 & & Model 3 & Model 4 & & Model 5 \\
\hline Intercept & $35.82^{* * *}$ & $38.14^{* * * *}$ & & $38.13^{* * *}$ & & $38.50^{* * * *}$ & $38.52^{* * *}$ & \\
\hline Time & $-.09^{*}$ & -.06 & & -.09 & & -.07 & -.08 & \\
\hline \multicolumn{9}{|l|}{ Predictors of BMI Intercept } \\
\hline Gender & & $-1.99 *$ & & $-1.99^{*}$ & & $-2.05^{*}$ & $-2.06^{*}$ & \\
\hline Marital satisfaction & & .00 & & .03 & & & & \\
\hline Problem solving & & & & .03 & .06 & & & \\
\hline Marital satisfaction* gender & & & -.05 & & & & & \\
\hline Problem solving* gender & & & & & -.06 & & & \\
\hline \multicolumn{9}{|l|}{ Predictors of BMI slope } \\
\hline Gender & & $.16^{\dagger}$ & & $.17^{\dagger}$ & & .14 & .14 & \\
\hline Marital satisfaction & & -.02 & & $-.05^{*}$ & & & & \\
\hline Problem Solving & & & & -.03 & $-.06^{*}$ & & & \\
\hline Marital Satisfaction* gender & & & $.06^{*}$ & & & & & \\
\hline Problem solving* gender & & & & & $.06^{\dagger}$ & & & \\
\hline Intercept/slope variance & $55.78 / .22$ & $48.07 / .19$ & & $48.10 / .18$ & & $47.86 / .18$ & $47.84 / .18$ & \\
\hline$-2 \mathrm{LL}$ & 3903 & 3306 & & 3311 & & 3333 & 3338 & \\
\hline
\end{tabular}

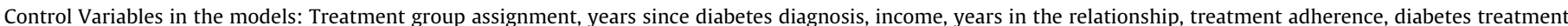
type, baseline glycemic control, and age.

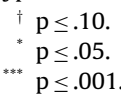

Panel A: Marital Satisfaction by Gender Predicting BMI for Females and Males
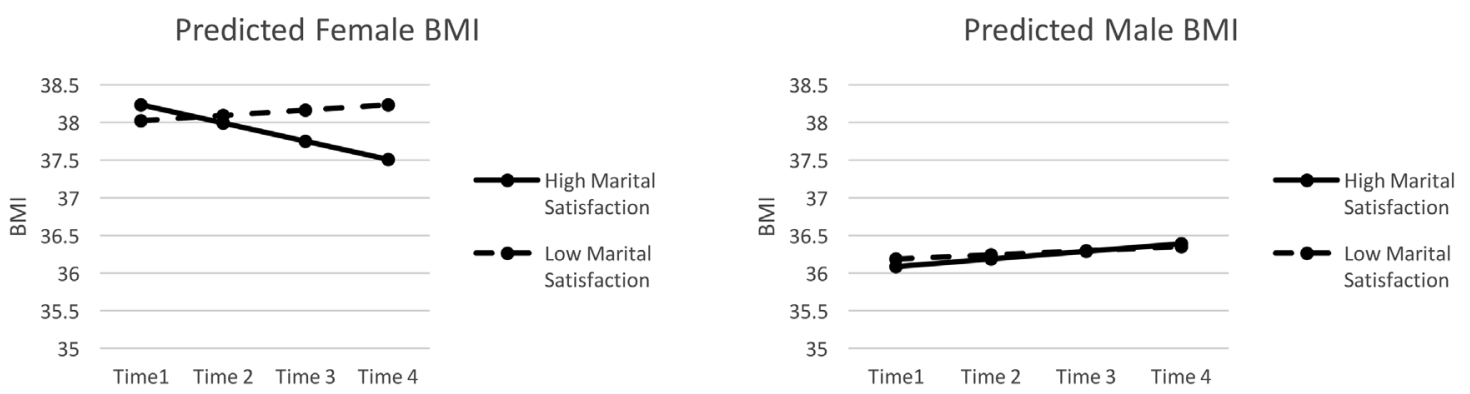

Panel B: Positive Problem Solving by Gender Predicting BMI for Females and Males
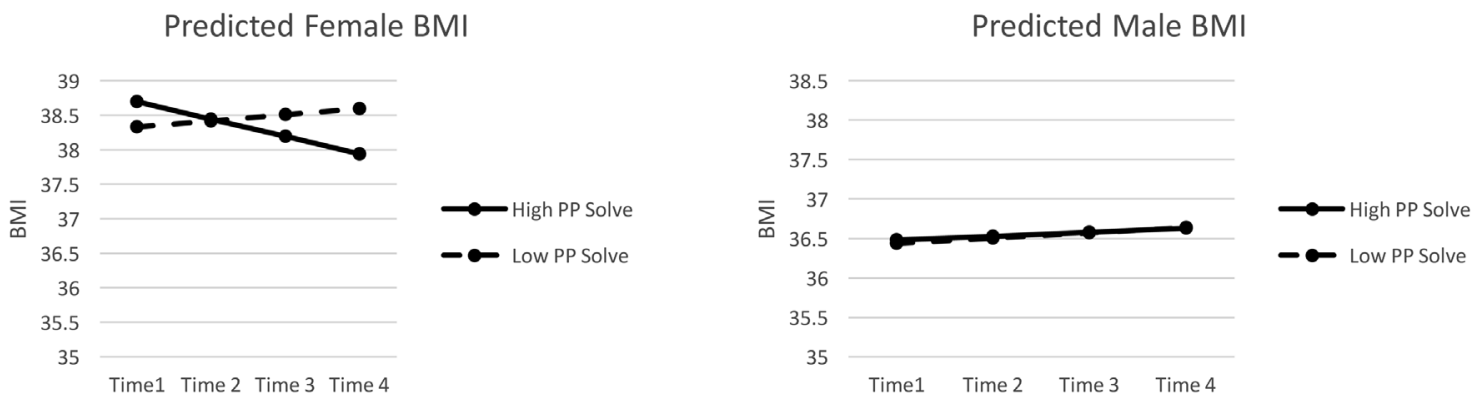

Fig. 1. Plots of gender interactions with marital satisfaction and positive problem solving predicting BMI across time.

Note: PP Solve $=$ Positive Problem Solving

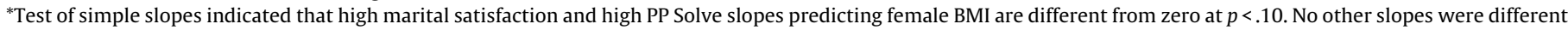
from zero.

tionship processes were not related to changes in BMI for any relationship process scales in any treatment arm.

\section{Discussion}

Higher relationship satisfaction and positive problem solving scores prior to treatment predicted decreases in BMI across time for female participants. The context of weight and diabetes management for many patients is centered in partner relationships [9].
Research has suggested that higher relationship quality is linked with better glycemic control (lower A1C), and better diabetes management [10]. However, research on relationship quality and BMI has been mixed [11]. The current study adds to prior research and provides some clarifications as well, with results showing that, for females with T2D, BMI decreases at a steeper rate when relationship satisfaction and positive problem solving are higher. In clinical terms, the change in BMI was statistically significant though small (1/10th of a standard deviation). 
Relationship well-being may be more relevant to BMI decrease for females than for males with T2D. Some describe women as more emotionally aware of relational issues [12], perhaps leading to greater awareness of positive relational processes that help with weight loss, or to the internalizing of negative affect in relationships [13] potentially contributing to unhealthy eating. We note that the intervention was focused on glycemic control, with weight loss as secondary, and results may have been different if weight loss was the primary target.

\section{Conclusion}

Women with T2D involved in behavioral interventions may benefit when efforts are made to enhance relationship satisfaction and promote positive problem solving. Future research should consider other contributors to weight loss (e.g., diet, exercise) and how they are impacted by relationship processes.

\section{Funding}

Funding for this study was provided by the National Institutes of Health (NIDDK): 1R18DK080867-01A

\section{Ethical statement}

The trial was approved by the Institutional Review Boards at all appropriate institutions. The research protocol was approved by the appropriate Institutional Review Boards.

\section{Statement of conflicts of interest}

None.

\section{Trial registration}

ClinicalTrials.gov NCT01017523.

\section{Acknowledgements}

We would like to acknowledge the late Jacqueline Dimmock, Ph.D. for her invaluable help during this project.

\section{References}

[1] Schierberl Scherr AE, McClure Brenchley KJ, Gorin AA. Examining a ripple effect: do spouses' behavior changes predict each other's weight loss? J Obes 2013;2013:297268. https://www.hindawi.com/journals/jobe/2013/297268/.

[2] Fisher L, Wiehs KL. Can addressing family relationships improve outcomes in chronic disease? Report of the National Working Group on Family-based Interventions in Chronic Disease. J Fam Pract 2000;49:561-6.
[3] Murawski ME, Milson VA, Ross KM, Rickel KA, DeBraganza N, Gibbons LM, et al. Problem solving, treatment adherence, and weight-loss outcomes among women participating in a lifestyle treatment for obesity. Eat Beh 2009:(3):146-51.

[4] Kurdek LA. Conflict resolution styles in Gay, Lesbian, and Heteroxexual nonparent, and Heterosexual parent couples. J Marriage Fam 1994;56:705-22.

[5] Trief PM, Fisher L, Sandberg JG, et al. Health and psychosocial outcomes of a telephonic couples behavior change intervention in patients with poorly controlled type 2 diabetes: a randomized clinical trial. Diab Care 2016;39(12):2165-73.

[6] Trief PM, Sandberg J, Fisher L, et al. Challenges and lessons learned in the development and implementation of a couples-focused telephone intervention for adults with type 2 diabetes: the Diabetes Support Project. Transl Behav Med $2011 ; 1: 461-7$.

[7] Busby DM, Christensen C, Crane DR, Larson JH. A revision of the Dyadic Adjustment Scale for use with distressed and nondistressed couples: construct hierarchy and multidimensional scales. J Marital Fam Ther 1995;21:289-308.

[8] Kievit R, Brandmaier A, Ziegler G, van Harmelen AL, de Mooij S, Moutoussis M, et al. Developmental cognitive neuroscience using Latent Change Score models: a tutorial and applications. bioRxiv 2017;110429. www.biorxiv.org/content/ biorxiv/early/2017/02/22/110429.full.pdf.

[9] Meltzer AL, Novak SA, McNulty JK, Butler EA, Karney BR. Marital satisfaction predicts weight gain in early marriage. Health Psychol 2013;32(7):824.

[10] Trief PM, Ploutz-Snyder R, Britton KD, Weinstock RS. The relationship between marital quality and adherence to the diabetes care regimen. Ann Behav Med 2004; $27: 148-54$

[11] Meltzer AL, McNulty JK, Karney BR. Social support and weight maintenance in marriage: the interactive effects of support seeking, support provision, and gender. J Fam Psychol 2012;26(5):678.

[12] Acitelli LK. Gender differences in relationship awareness and marital satisfaction among young married couples. Pers Soc Psychol Bull 1992;18(1):102-10.

[13] Katz LF, Gottman JM. Spillover effects of marital conflict: in search of parenting and co-parenting mechanisms. In: McHale JP, Cowan PA editors. Understanding how family-level dynamics affect children's development: studies of two-parent families. San Francisco, CA: Jossey-Bass; 1996. p. 57-76.

Jeremy B. Yorgason* Jonathan G. Sandberg School of Family Life, Brigham Young University, Provo, UT United States

Ruth S. Weinstock Paula M. Trief

The State University of New York Upstate Medical University, Syracuse, NY United States

Lawrence Fisher Danielle Hessler The University of California, San Francisco, CA United States

* Corresponding author at: School of Family Life, Brigham Young University, 2079 JFSB, Provo, UT, 84602, United States. E-mail address: jeremy_yorgason@byu.edu (J.B. Yorgason)

21 August 2019 